\title{
Diversidade de insetos e aranhas presentes em diferentes fisionomias no Pantanal, na seca e cheia, Corumbá, MS
}

\section{Insects and spiders diversity present in different physiognomies in the Pantanal, the dry and wet, Corumbá, MS}

Diversidad de insectos y arañas presente en diferentes fisionomías del Pantanal, en seco y húmedo, Corumbá, MS

Adriano Schulz Lopes ${ }^{1}$

Suellen Soares ${ }^{2}$

Elizabete Maria da Silva ${ }^{3}$

Antonia Railda Roel ${ }^{4}$

${ }^{1}$ Graduando em Agronomia, Universidade Católica Dom Bosco (UCDB). E-mail: adrianoschulz@gmail.com

${ }^{2}$ Mestrado em Biotecnologia, UCDB. E-mail: soares.s18@gmail.com

${ }^{3}$ Doutorado em Ciências Ambientais e Sustentabilidade Agropecuária, UCDB. E-mail: dasilvabete@yahoo.com.br

${ }^{4}$ Engenheira Agrônoma - Entomologista. Professora do Programa de Pós-Graduação, Mestrado e Doutorado Acadêmico em Ciências Ambientais e Sustentabilidade Agropecuária, UCDB. E-mail: arroel@ucdb.br 
Resumo: Objetivou-se inventariar as Ordens de insetos em diferentes fisionomias no Pantanal, Corumbá, MS, durante dois meses, em período de seca e cheia. Foram comparadas quatro áreas, Mata ciliar, Paratudal, Espinheiral e Canjiqueiral. As coletas foram obtidas de armadilhas de Malaise, e os insetos capturados foram acondicionados em frascos e preservados em álcool 96\%, e identificados até ordem e morfoespécies. Foram capturados 13.883 exemplares pertencentes a seis Ordens. Na Mata ciliar foram capturados 580 indivíduos, no Paratudal 6.696 indivíduos, no Espinheiral 3.052 e no Canjiqueiral 3.515 indivíduos, pertencentes ao período de seca e cheia, em abril e maio de 2013. Foi possível demonstrar a abundância e riqueza de Ordens de insetos presentes nessas fisionomias e a eficiência da armadilha de Malaise em coletar insetos nas fisionomias do Pantanal. Há abundância e diversidade de insetos e aranhas no Pantanal na seca e na cheia.

Palavras-chaves: diversidade de insetos, planície inundável, riqueza de insetos.

Abstract: The objective inventory of insects orders in different physiognomies in the Pantanal, Corumbá, MS, for two months, in dry and wet period. Four areas were compared, Riparian vegetation, paratudal, Espinheiral and Canjiqueiral. The samples were obtained from Malaise traps and insects captured were placed in jars and preserved in alcohol $96 \%$, and identified to order and morphospecies. They were captured 13883 specimens belonging to six orders. In Riparian forest were captured 580 individuals, in paratudal 6 696 individuals in Espinheiral 3052 and Canjiqueiral 3515 individuals belonging to the drought and flood, in April and May 2013. It was possible to demonstrate the abundance and richness of Orders insects in those faces and efficiency of Malaise trap to collect insects in the Pantanal faces. There is abundance and diversity of insects and spiders in the Pantanal in the dry and in full.

Key words: insect diversity, flood plain, insect wealth.

Resumen: El objetivo se inventariar las órdenes de insectos en diferentes fisonomías en el Pantanal, Corumbá, MS, durante dos meses, en el período seco y húmedo. Cuatro áreas fueron comparadas, la vegetación de ribera, paratudal, Espinheiral y Canjiqueiral. Las muestras se obtuvieron de trampas Malaise y los insectos capturados fueron colocados en frascos y se conservaron en alcohol al $96 \%$, e identificados a la orden y morfoespecies. Fueron capturados 13883 ejemplares pertenecientes a seis órdenes. En Bosque de ribera se capturaron 580 individuos, en paratudal 6696 individuos en Espinheiral 3052 y Canjiqueiral 3515 individuos pertenecientes a la sequía y las inundaciones, en abril y mayo de 2013. Fue posible demostrar la abundancia y riqueza de las Órdenes insectos presentes en esas fisionomías y la eficiencia de la trampa Malaise para recoger los insectos en las fisionomías de Pantanal. Hay abundancia y diversidad de insectos y arañas en el Pantanal en seco y en húmedo.

Palabras clave: diversidad de insectos, llanura de inundación, riqueza de insectos. 


\section{INTRODUÇÃO}

O Brasil possui a maior biodiversidade do planeta, entretanto a viabilidade dos ecossistemas está sendo ameaçada pela fragmentação dos remanescentes. Essa prática tem como consequência a perturbação do equilíbrio dinâmico entre as espécies e o ambiente, ocasionando extinções.

A perda da biodiversidade ameaça a sustentabilidade de todo o sistema, com uma consequente redução dos serviços ambientais, tais como controle de pragas, ciclagem de nutrientes e manutenção da estrutura do solo, ocasionando até mesmo alterações no ciclo hidrológico.

No grande Filo Arthropoda, a Classe Insecta compreende o maior grupo dos seres vivos conhecidos, representa cerca de $70 \%$ das espécies animais, sendo foco de estudos as interações entre os organismos e o meio onde vivem distribuídos nos diversos biomas e determinado por diversos fatores. A Ordem Hymenoptera é um grupo de grande abundância, apresentam uma grande diversidade de padrão de vida, nichos ecológicos e níveis de sociabilidade, mas pouco conhecido em nível de espécie.

Os Hymenoptera parasitoide são comuns e abundantes em todos os sistemas terrestres e desempenham importante papel na regulação da população de pragas. Dentre os Hymenoptera, há os parasitoides e predadores que são ecologicamente importantes, pois, além de serem agentes reguladores de diversos grupos de insetos, servem como indicadores da presença ou ausência dessas populações. No plano econômico, o grupo oferece alternativas para o controle de insetos-praga para a agricultura através de inimigos naturais, minimizando o uso de agroquímicos.

Pelo exposto, é extremamente relevante o presente estudo, relacionado à diversidade de insetos e aranhas no bioma Pantanal, uma das maiores extensões úmidas contínuas do planeta. 


\section{PANTANAL E A SUA DIVERSIDADE DE INSETOS}

O Pantanal é formado por conjuntos de grandes depressões e leques aluviais na bacia do rio Paraguai, onde se convertem as mais importantes províncias fitogeográficas do continente: Floresta Amazônica, Cerrado, Charco e Floresta Atlântica (AMADOR, 2006). É uma das maiores planícies de sedimentação do globo (SILVA, 2003), está situado quase que inteiramente em territórios brasileiros (ADÁMOLI, 1982). Em território nacional possui 140000 km², com 65\% do seu território no Estado de Mato Grosso do Sul e 35\% em Mato Grosso (CASTELNOU et al., 2003). É constituído por planície aluvial sujeita a alternâncias de períodos de seca e enchentes anuais e plurianuais (BRASIL, 1972), considerado a maior área inundável do continente americano (SOUZA, 1978).

Apresenta temperaturas elevadas durante o ano todo e duas estações bem definidas: sendo uma a seca, de abril a setembro, e outra a chuvosa, de novembro a março, com média anual das precipitações em torno de 800 a 1200 mm. As taxas de evapotranspiração são bastante altas e superam os índices pluviométricos, caracterizando deficiência hídrica anual superior a 300 mm (ALFONSI; CAMARGO, 1986).

A estiagem representa a ausência total de chuvas, independente da estação do ano, fato que ocorre na região do Pantanal. A estação da seca pode ser mais ou menos intensa, dependente da distribuição/ intensidade das chuvas que é variável dentro e entre anos e sub-regiões do Pantanal (SANTOS et al., 2009).

As plantas e os animais no Pantanal são adaptados às cheias e secas anuais, e essas irregularidades extremas representam estresse adicional para os organismos que habitam a região. A mortalidade natural das populações durante tais períodos é muito elevada, suas secas prolongadas provocam mortalidade elevada nos estoques de 
Diversidade de insetos e aranhas presentes em diferentes fisionomias no Pantanal, na seca e cheia, Corumbá, MS

animais aquáticos e pressionam os animais a se concentrarem nas proximidades de poças de água e canais restantes na busca de alimentos. Durante essa fase, as queimadas inadequadas prejudicam ainda mais o estresse dos animais (SANTOS et al., 2009).

No período da seca, os campos dessa região constituem fontes de alimentos fartos principalmente para os bovinos. Os animais voltam para próximo dos leitos alagados, e os que não conseguem retornar ficam presos em lagoas pequenas tornando-se alimentos fáceis para outras espécies de animais, e as baías que se formam acumulam uma quantidade grande de peixes (ALMEIDA, 2002).

Em relação aos insetos, de acordo com Thomanzini e Thomanzini (2002) estes são considerados bons indicadores, ou seja, bioindicadores de impacto ambiental, devido a sua grande diversidade de espécies e habitat, além da sua importância nos processos biológicos dos ecossistemas naturais. Além de ser o grupo de animais mais numerosos do globo terrestre, apresentam grande diversidade, em termos de espécies e de habitats e grande variedade de habilidades para dispersão e seleção de hospedeiros e de respostas à qualidade e quantidade de recursos disponíveis.

O termo bioindicador pode ser usado para indicar alteração de habitats, destruição, contaminação, reabilitação, sucessão da vegetação, mudanças climáticas e, consequentemente, degradação dos solos e ecossistemas (MCGEOCH, 1998). Os bioindicadores, ainda, segundo Allaby (1992), são espécies que podem ter uma amplitude estreita em relação aos fatores ecológicos e, quando presentes, podem indicar uma condição ambiental particular ou estabelecida.

Considerando que bioindicadores, cujas funções vitais são tão estreitamente correlacionadas com os fatores abióticos, podem ser utilizados como indicadores de mudanças desses fatores, é de grande valia o estudo desses organismos. Para tanto, é importante o monitoramento ambiental e indicação da necessidade de práticas de manejo 
que visem à conservação das populações de insetos (PIMENTA, 2008). Segundo Garlet, Roman e Costa (2006), o conhecimento da entomofauna de uma área ou região tem grande importância para a obtenção de maiores informações a respeito do comportamento das espécies e da relação existente entre inseto e ambiente. Para Pulz et al. (2007), o conhecimento da entomofauna em um agroecossistema possibilita a compreensão da dinâmica das interações ecológicas permitindo estabelecer manejos adequados.

Os insetos menores são mais sensíveis, diminuindo ou até desaparecendo após uma perturbação no ambiente. Nesse contexto, citam-se os insetos de solo e serapilheira, como microlepidópteros, microhimenópteros, besouros detritívoros, pequenas formigas. Segundo Brown (1997), os indivíduos ou espécies das ordens Orthoptera, Hemiptera, Diptera, Lepidoptera, Hymenoptera e Coleoptera constituem os mais importantes bioindicadores. Essas ordens de insetos contêm subgrupos importantes adaptados para testar níveis de poluição, redução de predadores, aumento de plantas invasoras, inibição da decomposição (BROWN, 1997).

Dessa forma, objetivou-se, por meio do presente trabalho, avaliar a diferença das Ordens do Pantanal em diferentes fisionomias no período de seca e cheia coletados em armadilhas de Malaise. Busca-se responder a algumas questões: a) Quais grupos compõem a entomofauna nos diferentes ambientes? b) Existe diferença na riqueza entre as diferentes áreas estudadas? c) Existe diferença na abundância entre as diferentes áreas estudadas?

\section{MATERIAL E MÉTODOS}

\section{1 Área de Estudo}

Este trabalho foi realizado na Fazenda São Miguel, localizada na Estrada Parque Pantanal Km 08, na região de Corumbá, Mato Grosso 
do Sul, com coletas mensais de insetos por meio de armadilha Malaise em quatro fisionomias do Pantanal, Mata ciliar, Paratudal, Canjiqueiral e Espinheiral, durante abril e maio de 2013.

A fazenda possui uma área de 620 ha no perímetro do município de Corumbá, MS, distante 403 Km da capital, sob coordenadas geográficas, (190'35"S, 57³9'17"O e altitude de 159 metros). Na região de Corumbá, predomina o clima tropical do tipo Aw, de acordo com a classificação de Köppen-Geiger, e é caracterizado por clima tropical com estação seca pronunciada e com precipitação média anual entre 1000 e 1400 mm (SILVA; FONTENELLE; MARTINS, 2000).

A fazenda São Miguel utiliza cerca de 60\% de sua área para a criação de gado, nesta predominam forrageiras Brachiaria spp. À margem da fazenda, passa o curso principal do Rio Paraguai, que é fonte de abastecimento de água para as comunidades urbanas das cidades de Corumbá.

Na região, o período mais intenso de chuvas ocorre de novembro a março, ocasionando um período de inundação com início em dezembro e pico máximo em fevereiro. As temperaturas médias oscilam entre $23^{\circ} \mathrm{C}$ e $25^{\circ} \mathrm{C}$ e variam conforme as estações do ano, podendo atingir temperaturas de $10 \mathrm{C} \cong$ a $35 \mathrm{C} \cong$ ( $\mathrm{min} / \max$ ) no verão. No ano de 2013, as cheias foram atípicas, com a seca em janeiro a abril, e a cheia em maio a setembro.

\subsection{As fisionomias}

As coletas foram realizadas em quatro diferentes fisionomias da fazenda São Miguel. O estudo foi realizado em áreas de Mata ciliar, Paratudal, Espinheiral e Canjiqueiral.

A área de Mata ciliar atende ao que é pedido pela lei, sendo que os rios com menos de $10 \mathrm{~m}$ de largura devem ter $30 \mathrm{~m}$ de vegetação que margeia as nascentes e cursos de água em cada margem. A vegetação 
é densa, com dossel variado em diferentes locais, em determinados locais, ocorre à predominância das espécies Cassia occidentalis L. (fedegoso, fedegoso verdadeiro, mamangá, mato-pasto), pertencente à família Fabaceae, espécie arbustiva, assim como a Sphagneticola trilobata (arnica-do-mato, vedélia, margaridão), pertencente à família Asteraceae, além de espécies herbáceas, anuais ou perenes, subarbustivas ou arbustivas (ALMEIDA et al., 1998).

A área de Paratudal tem como espécie arbórea dominante o paratudo Tabebuia aurea, popularmente conhecida por caraíba, ipê-do-cerrado, entre outros nomes regionais. Também conhecido, o ipê-amarelo Tabebuia chrysotricha é também dominante em áreas de mata de galeria no domínio do Cerrado (OLIVEIRA; SCHELEDER; FAVERO, 2008). Esse gênero contém espécies de árvores da família das Bignoniáceas, geralmente encontradas no Cerrado e no Pantanal. A área de Paratudal, possui uma vegetação característica com espécies arbóreas dominantes que, muitas vezes, crescem sobre murundus, que constituem pequenas elevações de terra produzidas por formigas. Essa fisionomia é caracterizada pela alta diversidade e densidade de espécies vegetais e destaca-se pela sua intensa floração (SOARES; OLIVEIRA, 2009).

A área de Espinheiral é constituída por um estrato arbustivo dominado por espécies espinhosas (arbustivas e trepadeiras) (POTT; POTT, 1994). Atualmente, essa fitofisionomia não é utilizada para pastejo bovino, chegando a ser quase impenetrável. Tem como espécie dominante a Mimosa pudica L. conhecida como dormideira, arranhadeira, que são ervas daninhas das pastagens. São facilmente encontradas em qualquer tipo de solo e denominadas como arbustos pequenos e pertencentes à família das Leguminosae/Fabaceae. Outras espécies também são encontradas como a Lippia alba (Mill.) (Verbenaceae) distribuída no Brasil e conhecida como erva-cidreira brasileira, alecrim do campo ou alecrim selvagem. 
A área de Canjiqueiral possui, em especial, espécies de porte arbustivo que domina uma extensa área de vegetação, as chamadas canjiqueiras, tendo uma baixa diversidade e uma alta representação de uma única espécie dominante (LORENZI, 1992). Essa fisionomia possui espécies de porte arbustivo, que é responsável por dominar extensas áreas de vegetação, sendo popularmente conhecida no Pantanal como canjiqueira Byrsonima orbignyana A. Juss. É uma árvore frutífera de pequeno porte, sendo da família Malpighiacea. Outra também predominante na região é a Richardia grandiflora (Cham. \& Schldl.) Steud. (Rubiaceae), conhecida popularmente como poaia-rasteira e ipeca-mirian. São espécies herbáceas anuais que se desenvolvem em todo o país, inclusive no Pantanal e em áreas com pastagem.

\subsection{Coleta de dados}

As coletas foram realizadas mensalmente com armadilha tipo Malaise durante dois meses (abril e maio de 2013). Em cada um dos quatro locais, Mata ciliar, Paratudal, Espinheiral e Canjiqueiral, foram obtidas mensalmente amostras das armadilhas Malaise, totalizando oito amostras. As armadilhas permaneceram em campo (uma armadilha por fisionomia) durante todo o período das coletas (30 dias).

Esse tipo de armadilha funciona para interceptar o voo dos insetos que tendem a se dirigir para a região superior, que contém um frasco coletor contendo líquido (álcool ou outra substância), onde os insetos são aprisionados. Entretanto captura também outros artrópodes, especialmente aranhas. A armadilha consiste em uma tenda de tecido com malha fina (como filó, por exemplo), com coletores na extremidade superior. Os insetos são atraídos, ou estão voando quando esbarram no filó, e tendem a subir entrando nos coletores, de onde não podem sair. 
Os insetos e as aranhas capturados foram recolhidos de cada armadilha separadamente, acondicionadas nos frascos coletores, marcadas com dados da coleta (mês, área, data da coleta), e triados manualmente com auxílio de lupa binocular (estereomicroscópio). Dentre os da Ordem Hymenoptera, separou-se os da Família Formicidae, para identificar somente predadores, parasitoides e apiformes (polinizadores), e estes ficaram separados ainda na contagem. Optou-se ainda por mensurar as aranhas, por estas serem sempre presentes nas amostragens.

Os exemplares, previamente preservados em álcool a 96\% e etiquetados, foram incorporados à Coleção de Zoologia da Universidade Federal de Mato Grosso do Sul. A identificação das Ordens foi realizada no Laboratório de Entomologia da Universidade Católica Dom Bosco (UCDB) e, na identificação taxonômica do material coletado, foram utilizadas (Gallo et al., 2002) somente para identificação dos insetos.

\subsection{Análise de dados}

\subsection{1 Índice faunístico aplicado às Ordens de Insetos}

\subsubsection{Frequência Relativa}

Esse índice representou a porcentagem do número de indivíduos, em relação ao total de indivíduos coletados, conforme fórmula abaixo (SILVEIRA NETO et al., 1976):

\section{$F=n / N \times 100$}

Onde $\mathrm{F}$ = porcentagem de frequência;

$\mathrm{n}$ = número de indivíduos de cada superfamília;

$\mathrm{N}=$ número total de indivíduos coletados. 


\subsubsection{2 Índice de Diversidade de Riqueza de Margalef - Riqueza de Espécies}

A riqueza de morfoespécies refere-se à abundância numérica de uma determinada área geográfica, região ou comunidade. A medida utilizada para a definição de riqueza de morfoespécies, no estudo, foi o índice de Margalef, dado por:

$$
D_{M g}=(S-1) / \ln N
$$

Onde S é o número de morfoespécies registrada;

$\mathrm{N}$ é o número total de indivíduos.

\section{RESULTADOS E DISCUSSÃO}

\subsection{As fisionomias e épocas de coleta}

O método de amostragem por armadilhas do tipo Malaise mostrou-se viável para a avaliação da entomofauna de insetos pertencente às fisionomias, nos períodos de seca e cheia. Capturam ainda aranhas, também considerado um grupo de bom indicador de variações ambientais.

Foram coletados 13883 insetos e aranhas nas armadilhas do tipo Malaise sendo (7 527 no período da seca (abril)) e (6.383 no período da cheia (maio)). Dentre os insetos, as Ordens mais abundantes foram Hymenoptera (3.270) - quando adicionado Formicidae às coletas - e Diptera. Entretanto a Família Formicidae foi retirada da análise por sua abundância de formas e de hábitos alimentares. Foram coletados 2.446 Diptera, e 2.089 Hymenoptera entre as duas coletas. Nesse caso, tanto na seca como na cheia, foram coletadas Diptera (4.731) e Hymenoptera (exceto Formicidae) (3.497). Somente pertencentes à Família Formicidae foram capturados 2.020 indivíduos, mas estes não foram identificados nos seus grupos e ou hábitos alimentares. 
No Paratudal, foram capturados 6.710 indivíduos, no Canjiqueiral 3.535 indivíduos, no Espinheiral 3.071 indivíduos e, na Mata ciliar, 594 indivíduos pertencentes ao período da seca e cheia (Tabela 1 e 2 respectivamente).

Tabela 1 - Insetos e aracnídeos capturados em armadilhas Malaise no período da seca em diferentes fisionomias no Pantanal, Corumbá, MS, no período de abril e maio 2013

\begin{tabular}{lccccc}
\hline \multicolumn{1}{c}{ Táxons } & Paratudal & Canjiqueiral & Espinheiral & Mata ciliar & $\begin{array}{c}\text { Total de } \\
\text { Indivíduos }\end{array}$ \\
\hline Hymenoptera* & $1.203(177)$ & $672(158)$ & $195(75)$ & $19(17)$ & $2.089(427)$ \\
Formicidae & 521 & 279 & 308 & 73 & 1.181 \\
Lepidoptera & $336(39)$ & $161(12)$ & $81(12)$ & $8(3)$ & $586(66)$ \\
Diptera & $803(42)$ & $775(22)$ & $794(24)$ & $74(8)$ & $2.446(96)$ \\
Coleoptera & $318(47)$ & $65(22)$ & $161(24)$ & $19(8)$ & $563(101)$ \\
Hemiptera & $382(48)$ & $88(15)$ & $123(20)$ & $16(10)$ & $609(93)$ \\
Orthoptera & $19(5)$ & $5(2)$ & $15(7)$ & - & $39(14)$ \\
Aranae & $5(4)$ & $5(5)$ & $3(2)$ & $1(1)$ & $14(12)$ \\
(Arachnida) & 3.587 & 2.050 & 1.680 & 210 & $7.527(809)$ \\
\hline Total & & & & \\
\hline () Morfoespécies & & & & & \\
* Obs. Exceto Formicidae & &
\end{tabular}

Tabela 2 - Insetos e aracnídeos capturados em armadilhas Malaise no período da cheia em diferentes fisionomias no Pantanal, Corumbá, MS, no período de abril e maio 2013

\begin{tabular}{lccccc}
\hline \multicolumn{1}{c}{ Táxons } & Paratudal & Canjiqueiral & Espinheiral & $\begin{array}{c}\text { Mata } \\
\text { ciliar }\end{array}$ & $\begin{array}{c}\text { Total de } \\
\text { Indivíduos }\end{array}$ \\
\hline Hymenoptera* & $761(81)$ & $431(84)$ & $188(69)$ & $28(19)$ & $1.408(253)$ \\
Formicidae & 230 & 252 & 287 & 70 & 839 \\
Lepidoptera & $204(25)$ & $130(12)$ & $61(17)$ & $48(2)$ & $443(56)$ \\
Diptera & $1.180(32)$ & $456(23)$ & $501(26)$ & $148(11)$ & $2.285(92)$ \\
Coleoptera & $219(38)$ & $123(26)$ & $195(20)$ & $39(10)$ & $576(94)$ \\
Hemiptera & $499(41)$ & $70(19)$ & $113(30)$ & $30(15)$ & $712(105)$
\end{tabular}


Diversidade de insetos e aranhas presentes em diferentes fisionomias no Pantanal, na seca e cheia, Corumbá, MS

\begin{tabular}{lccccc}
\hline \multicolumn{1}{c}{ Táxons } & Paratudal & Canjiqueiral & Espinheiral & $\begin{array}{c}\text { Mata } \\
\text { ciliar }\end{array}$ & $\begin{array}{c}\text { Total de } \\
\text { Indivíduos }\end{array}$ \\
\hline $\begin{array}{l}\text { Orthoptera } \\
\text { Aranae }\end{array}$ & $21(6)$ & $8(3)$ & $30(7)$ & $8(4)$ & $67(20)$ \\
(Arachnida) & $9(5)$ & $15(7)$ & $16(9)$ & $13(6)$ & $53(27)$ \\
\hline Total & 3.123 & 1.485 & 1.391 & 384 & $6.383(647)$ \\
\hline $\begin{array}{l}\text { () Morfoespécies } \\
\text { *Obs. Exceto Formicidae }\end{array}$ & & & & \\
\end{tabular}

No período da seca, as fisionomias de Paratudal, Canjiqueiral e Espinheiral apresentaram abundância mais elevada de insetos com 3.587, 2.050, 1.680 indivíduos no total respectivamente, em relação à Mata ciliar que obteve um total de 210 indivíduos. Embora a Mata ciliar apresente uma grande diversidade de plantas, o acesso à armadilha se tornou um obstáculo ao voo, o que pode explicar essas diferenças.

Enquanto no período de cheia, as fisionomias de Paratudal, Canjiqueiral e Espinheiral também apresentaram abundância elevada de insetos com 3.123, 1.485 e 1.391 indivíduos respectivamente no total, em relação à Mata ciliar que obteve um total de 384 indivíduos (Tabela 3), semelhante à proporção obtida no período da seca.

Tabela 3 - Frequência relativa total de insetos e aracnídeos capturados em armadilha Malaise no período de seca e cheia em diferentes fisionomias no Pantanal, Corumbá, MS, no período de abril e maio de 2013

\begin{tabular}{lcccc}
\hline \multicolumn{5}{c}{ Número de insetos capturados no período de seca e cheia } \\
\hline \multicolumn{1}{c}{ Táxons } & $\begin{array}{c}\text { Abundância } \\
\text { (seca) }\end{array}$ & $\begin{array}{c}\text { Frequência } \\
\text { relativa (\%) }\end{array}$ & $\begin{array}{c}\text { Abundância } \\
\text { (cheia) }\end{array}$ & $\begin{array}{c}\text { Frequência } \\
\text { relativa (\%) }\end{array}$ \\
\hline Hymenoptera & 2.089 & 27,75 & 1.408 & 22,05 \\
Formicidae & 1.181 & 15,69 & 839 & 13,14 \\
Lepidoptera & 586 & 7,78 & 443 & 6,94 \\
Diptera & 2.446 & 32,49 & 2.285 & 35,79
\end{tabular}




\begin{tabular}{|c|c|c|c|c|}
\hline \multicolumn{5}{|c|}{ Número de insetos capturados no período de seca e cheia } \\
\hline Táxons & $\begin{array}{l}\text { Abundância } \\
\text { (seca) }\end{array}$ & $\begin{array}{l}\text { Frequência } \\
\text { relativa (\%) }\end{array}$ & $\begin{array}{l}\text { Abundância } \\
\text { (cheia) }\end{array}$ & $\begin{array}{l}\text { Frequência } \\
\text { relativa (\%) }\end{array}$ \\
\hline Coleoptera & 563 & 7,47 & 576 & 9,02 \\
\hline Hemiptera & 609 & 8,09 & 712 & 11,15 \\
\hline Orthoptera & 39 & 0,51 & 67 & 1,04 \\
\hline Aranae (Arachnida) & 14 & 0,18 & 53 & 0,83 \\
\hline Total & 7.527 & & 6.383 & \\
\hline $\begin{array}{c}\text { Número de } \\
\text { morfoespécies }\end{array}$ & 809 & & 647 & \\
\hline
\end{tabular}

Em relação à abundância relativa entre as Ordens amostradas, a Ordem Diptera, ao se retirar Formicidae de Hymenoptera, foi a mais abundante no período da seca nas fisionomias, principalmente, de Espinheiral com um total de $47,26 \%$ e no Canjiqueiral com 37,80\%. No período de cheia, a Ordem Diptera, em todas as fisionomias, apresentou a maior abundância, um percentual de 38,54\% na Mata ciliar e 37,78\% no Paratudal (Tabela 4 e 5).

Tabela 4 - Abundância relativa total de insetos e aracnídeos capturados em armadilha Malaise no período de seca em diferentes fisionomias no Pantanal, Corumbá, MS, no período de abril e maio de 2013

\begin{tabular}{lcccc}
\hline \multicolumn{1}{c}{ Táxons } & $\begin{array}{c}\text { Abundância relativa do período da seca (\%) } \\
\text { Paratudal }\end{array}$ & Canjiqueiral & Espinheiral & Mata ciliar \\
\hline Hymenoptera & 33,53 & 32,78 & 11,60 & 9,04 \\
Formicidae & 14,52 & 13,60 & 18,33 & 34,76 \\
Lepidoptera & 9,36 & 7,85 & 4,82 & 3,80 \\
Diptera & 22,38 & 37,80 & 47,26 & 35,23 \\
Coleoptera & 8,86 & 3,17 & 9,58 & 9,04 \\
Hemiptera & 9,82 & 4,29 & 7,32 & 7,61 \\
Orthoptera & 0,52 & 0,24 & 0,89 & 0,0 \\
Aranae & 0,13 & 0,24 & 0,17 & 0,47 \\
(Arachnida) & & & & \\
\hline
\end{tabular}


Diversidade de insetos e aranhas presentes em diferentes fisionomias no Pantanal, na seca e cheia, Corumbá, MS

Tabela 5-Abundância relativa total de insetos e aracnídeos capturados em armadilha Malaise no período de cheia em diferentes fisionomias no Pantanal, Corumbá, MS, no período de abril e maio de 2013

\begin{tabular}{lcccc}
\hline \multicolumn{1}{c}{ Táxons } & $\begin{array}{c}\text { Abundância relativa no período da cheia (\%) } \\
\text { Paratudal }\end{array}$ & $\begin{array}{ccc}\text { Canjiqueiral } \\
\text { Espinheiral }\end{array}$ & Mata ciliar \\
\hline Hymenoptera & 24,36 & 29,02 & 13,51 & 7,29 \\
Formicidae & 7,36 & 16,96 & 20,63 & 18,22 \\
Lepidoptera & 6,53 & 8,75 & 4,38 & 12,50 \\
Diptera & 37,78 & 30,70 & 36,01 & 38,54 \\
Coleoptera & 7,01 & 8,28 & 14,01 & 10,15 \\
Hemiptera & 15,97 & 4,71 & 8,12 & 7,81 \\
Orthoptera & 0,67 & 0,53 & 2,15 & 2,08 \\
Aranae & 0,28 & 1,01 & 1,15 & 3,38 \\
(Arachnida) & & & & \\
\hline
\end{tabular}

Através dos resultados obtidos neste trabalho, pode-se verificar que as Ordens de insetos apresentam padrão de abundância, fato comprovado por outros autores, visto que algumas Ordens foram mais expressivas em determinadas áreas e pouco representativas em outras. Carvalho et al. (2012) enfatizam que os Diptera constituem uma das maiores Ordens de insetos em abundância e riqueza de espécies em quase todos os lugares e ambientes. A representação entre as Ordens segue o padrão encontrado por Dutra e Marinoni (1994) no estado do Paraná, em áreas litorâneas, onde se observou que as seis Ordens mais abundantes foram Diptera (53.574 indivíduos), Lepidoptera (3.605), Hymenoptera (1.990), Homoptera (1.572), Coleoptera (1.083) e Collembola (605), perfazendo, respectivamente, $85,14 \% ; 5,73 \% ; 3,16 \% ; 2,50 \% ; 1,72 \%$ e $0,96 \%$ do total de insetos capturados. Em levantamento de Ordens de insetos no Cerrado, Oliveira, Morón e Frizzas (2008) coletaram 129.199 espécimes de insetos pertencentes a 18 ordens. As Ordens com as maiores porcentagens de espécimes foram Hymenoptera (54\%), Diptera (27\%), Coleoptera (8\%), Lepidoptera (4\%), Isoptera (4\%) e Hemiptera (2\%). 
As mudanças nos padrões de transporte de umidade e nas temperaturas, a variação na distribuição das chuvas exercem influência sobre as comunidades de insetos. Isso ocorre porque as condições climáticas possuem forte influxo sobre a atividade comportamental dos insetos (OBER; HAYES, 2008). A temperatura e a umidade influenciam positivamente e negativamente na atividade forrageadora de algumas espécies (SANTOS et al., 2009).

Embora muitas Ordens tenham ocorrido ao longo de toda a amostragem, algumas foram mais expressivas em determinada área e pouco representativas em outras, tanto no período de seca quanto no período de cheia. Essas áreas, por serem as mais conservadas da ação do homem e cercadas por baixadas alagada, são identificadas como áreas com abundância de Ordens de insetos. A maior diversidade de árvores nesses ambientes corresponde a maior quantidade de abrigos para muitos grupos de insetos, bem como maior quantidade de alimento.

Entretanto, em Aranae, o número de aranhas no período da seca não obedeceu a essa tendência com 5, 5, 3, 1 exemplares no Paratudal, Canjiqueiral, Espinheiral e Mata ciliar respectivamente (Tabela 1). Mas, no período da cheia, houve modificações, com 9, 15, 16 e 15 exemplares no Paratudal, Canjiqueiral, Espinheiral e Mata ciliar, respectivamente. Valores semelhantes foram observados quanto à abundância, em número e número de morfoespécies (Tabela 2). As aranhas que constituem um grupo abundante, normalmente possuem o hábito solitário, são predadores, e são considerados bons indicadores.

\subsection{Análise das Ordens por fisionomia e época de coleta}

Na Ordem Diptera observou-se maior número em quatro áreas no período de seca com $2.446(32,49 \%)$ indivíduos, seguido por Hymenoptera (exceto Formicidae) com 2.089 (27,75\%) (Tabela 3). 
Diversidade de insetos e aranhas presentes em diferentes fisionomias no Pantanal, na seca e cheia, Corumbá, MS

Entretanto, somente na Família Formicidae que pertence a Ordem Hymenoptera, foram registrados 1.181 indivíduos, ou seja, 15,69\% do total. Portanto, se estes fossem inseridos dentro da Ordem Hymenoptera, esta seria a Ordem com maior abundância. Estes foram separados dos demais pela abundância nas amostras e por possuírem hábitos alimentares distintos dos demais da Ordem, com formigas doceiras, cortadeiras e caçadoras. As demais Famílias de Hymenoptera pertencem grande parte ao grupo dos inimigos naturais, predadores ou parasitoides, ou de polinizadores Apiformes. Essa separação, portanto, facilita a visualização da dinâmica dos inimigos naturais e/ou polinizadores nas diferentes fisionomias e períodos de seca e cheia.

A Ordem Hymenoptera devido a sua grande abundância e por ocupar diversos ambientes, tem sido bastante estudada. Os representantes dessa ordem proporcionam uma grande diversidade de padrão de vida, nichos ecológicos e níveis de sociabilidade (CROZIER, 1997). Incluem muitas espécies fitófagas, predadoras, parasitoides e polinizadoras, desde organismos solitários até de organização social complexa. Poucos grupos de insetos têm tanta importância para o homem quanto os Hymenoptera (GAULD; BOLTON, 1988). Estima-se que conhecemos menos de $10 \%$ desse grupo e que se pode tornar, portanto, o grupo mais abundante da classe Insecta. Por esse motivo, as Famílias de Hymenoptera parasitoides, predadores e apiformes são consideradas importantes no controle de população de insetos e na polinização.

Poucos trabalhos foram registrados sobre essa Ordem no Pantanal, e não existe registro sobre parasitoides. Em levantamento desenvolvido na Reserva Particular do Patrimônio Natural Engenheiro Eliezer Batista, estado de Mato Grosso do Sul, grupos como abelhas, formigas e vespas, pertencentes à Hymenoptera foram registrados. As abelhas coletadas pertencem a 42 espécies e 25 gêneros, sendo Apis mellifera a mais abundante (50\% do total) (AOKI et al., 2012). 
Quanto às vespas aculeata, foram registradas 40 espécies nas famílias Vespidae, Pompilidae, Mulitildae, Scoliidae, Crabronidae, Shpecidae e Chrysididae, importantes predadores e polinizadores (AOKI et al., 2012). Sobre Formicidae, Demetrio, Silvestre e Aoki (2012) descreveram a coleta de 120 espécies.

A Família Formicidae (Hymenoptera) apresentou a menor abundância no período de seca na área de Canjiqueiral com 13,60\% e no período de cheia com 7,36\% na área de Paratudal. As formigas desempenham papéis importantes na dinâmica de muitos ecossistemas como dispersão (DALLING; WIRTH, 1998; LEAL; OLIVEIRA, 1998; LEAL, 2003) e predação de sementes (LEVERY; BYRNE, 1993; MOUTINHO et al., 1993), ciclagem de nutrientes (COUTINHO, 1984; BRENER; SILVA, 1995) e herbivoria (WIRTH et al., 2003). Além disso, as formigas interagem diretamente com uma série de organismos e são provavelmente os mais bem-sucedidos de todos os grupos de insetos.

A Família Formicidae é considerada um grupo de insetos organizados em sociedades elaboradas, ocupando quase que todos os ecossistemas terrestres em grandes proporções e alta diversidade, escolhidos frequentemente como bioindicadores. Em inventário desenvolvido na Reserva Particular do Patrimônio Natural Engenheiro Eliezer Batista, em Mato Grosso do Sul, foram coletadas 120 espécies, distribuídas em 43 gêneros, em nove subfamílias das 15 reconhecidas na região Neotropical. Estes são agrupados em grupos funcionais, cultivadores de fungos (cortadeiras), generalistas, patrulheiros, oportunistas, predadores, crípticos, coletores de exudatos e nômades (DEMÉTRIO; SILVESTRE; AOKI, 2012).

Em relação à abundância relativa na área de Paratudal no período da cheia, a Família Formicidae obteve porcentagem menor em relação às Ordens estudadas. Isso pode ser devido à distribuição dos indivíduos, que, em algumas situações, pode estar relacionada com os murundus, típicos dessa fisionomia. 
Diversidade de insetos e aranhas presentes em diferentes fisionomias no Pantanal, na seca e cheia, Corumbá, MS

Na Ordem Diptera, observou-se maior número (quando comparada a número de indivíduos) nas quatro áreas no período de cheia com 2.285 (35,79\%) indivíduos, seguindo por Hymenoptera (exceto Formicidae) com 1.408 (22,05\%). Somente na Família Formicidae observou-se 839 (13,14\%) (Tabela 3), sendo muito abundante em todas as fisionomias. Das duas Ordens e uma Família identificadas tanto no período de seca como na cheia, obteve-se uma frequência maior de Diptera, com 32,49\% no período de seca, e 35,79\% no período da cheia.

Segundo Santos et al. (2007), no Pantanal há um aumento considerável tanto de adultos quanto do número de larvas de Diptera, devido ao período de cheia, o que resulta da maior umidade presente nas fisionomias. Com o aumento do nível da água no período da cheia, provavelmente houve aumento da disponibilidade de alimentos, o que foi o principal fator que influenciou o aumento das Diptera, adultos e larvas, nas fisionomias. Assim, maior quantidade de indivíduos coletados no período da cheia está relacionada com grande quantidade de substrato para sua alimentação e sobrevivência.

Os dipteros adultos se alimentam de diversos líquidos de plantas ou animais, como recursos florais (néctar e pólen), a seiva ou o sangue; a maioria das espécies alimenta-se de néctar, mas muitas são hematófagas e outras são predadoras de outros insetos. A frequência de visitação desses dipteros está relacionada às estações do ano, abundância floral e condições climáticas (SOUZA-SILVA et al., 2001).

Justificando a grande ocorrência de Diptera, as larvas ocorrem em muitos tipos de habitats, mas a grande maioria vive em todos os tipos de habitats aquáticos, alimentando-se de plantas. As larvas predadoras vivem em muitos habitats diferentes na água, no solo ou sobre a vegetação. Segundo Didham (1997), vários grupos de Diptera contribuem para o funcionamento da comunidade em vários níveis tróficos, principalmente nas relações presa-predador e interações competitivas. 
A Ordem Coleoptera, que hoje compõe a Ordem mais abundante e rica de espécies descritas, mostrou-se pouco representativa nesse levantamento. Esse fato pode ser atribuído ao método de coleta. Entretanto Bello, Aoki e Vieira (2012) descreveram, em levantamento na Serra do Amolar em Mato Grosso do Sul, onde coletaram 5.215 indivíduos e 420 espécies de Coleoptera, utilizando cinco metodologias. Dentre elas, $80 \%$ destes foram capturados em guarda-chuvas entomológicos.

A Ordem Hemiptera teve uma menor captura, sendo essa maior no Paratudal e espinheiral. Esse grupo possui predadores e hematófagos, mas a maioria alimenta-se de plantas. Valores maiores foram encontrados na época da cheia, ao contrário das demais ordens, com 712 e 609 indivíduos respectivamente.

A ordem em menor amostragem foi Orthoptera com 39 e 67 indivíduos total para a época seca e cheia respectivamente. A maioria destes são fitófagos, mas há predadores.

Apesar de serem terrestres, as aranhas foram capturadas em maior número na época das águas com 14 e 53 respectivamente. Como predadores, exclusivamente, essas são ótimos bioindicadores. Quanto às fisionomias, o padrão de ocorrência foi o mesmo que para os grupos de insetos, com maiores ocorrências no Paratudal e Cangiqueiral, do que no Espinheiral e Mata Ciliar.

\subsection{A riqueza de espécies por taxon: as fisionomias, épocas de coleta}

Comparando-se o número de Ordens capturadas por meio de armadilha Malaise, constatou-se, neste estudo, uma considerável quantidade de morfoespécies, demonstrando o grande potencial da entomofauna nas áreas amostradas. Assim, é de fundamental importância a realização de novos levantamentos da entomofauna para grupos específicos, havendo poucas informações sobre a diver- 
sidade do Pantanal. Além disso, faz-se necessário um estudo mais aprofundado sobre a composição faunística de insetos no Pantanal, utilizando maior número de pontos de coleta para que se tenham dados mais representativos.

Comparando o índice de riqueza entre as duas áreas, seca e cheia, nos quatro ambientes, observou-se que apesar da área de Mata Ciliar apresentar um número de morfoespécies menor que as outras áreas, esta fisionomia representa riqueza de morfoespécies maior que nas outras áreas com um índice de Margalef de R = 358 . Quanto à área de Espinheiral, esta ficou em segundo, com um índice de $R=2$ 709, levando em consideração que seu número de morfoespécies foi maior. Já na área cheia, esse índice de riqueza teve uma pequena alteração, Mata Ciliar com $R=3286$ contra $R=2678$ na área do Espinheiral (Tabela 6 e 7).

Tabela 6 - Índice de Diversidade de Riqueza de Margalef de Ordens (Morfoespécies) de insetos e aracnídeos capturados em armadilha Malaise no período da seca nas diferentes fisionomias no Pantanal, Corumbá, MS, no período de abril e maio de 2013

\begin{tabular}{lcccc}
\hline \multicolumn{1}{c}{ Taxons } & \multicolumn{3}{c}{ ÁREA SECA } & \\
Paratudal & Canjiqueiral & Espinheiral & Mata ciliar \\
\hline Hymenoptera & 177 & 158 & 75 & 17 \\
Lepidoptera & 39 & 12 & 12 & 3 \\
Diptera & 42 & 22 & 24 & 8 \\
Coleoptera & 47 & 22 & 24 & 8 \\
Hemiptera & 48 & 15 & 20 & 10 \\
Orthoptera & 5 & 2 & 7 & 0 \\
Aranae (Arachnida) & 4 & 5 & 2 & 1 \\
N* & 362 & 236 & 164 & 47 \\
S** & 7 & 7 & 7 & $\mathbf{3 . 5 8 8}$ \\
\hline Riqueza de Margalef & $\mathbf{2 . 3 4 5}$ & $\mathbf{2 . 5 2 9}$ & $\mathbf{2 . 7 0 9}$ & \\
* Numero total de indivíduos & & & \\
$* *$ Numero total de Táxons & & & &
\end{tabular}


Tabela 7 - Índice de Diversidade de Riqueza de Margalef de Ordens (Morfoespécies) de insetos e aracnídeos capturados em armadilha Malaise no período da cheia nas diferentes fisionomias no Pantanal, Corumbá, MS, no período de abril e maio de 2013

\begin{tabular}{|c|c|c|c|c|}
\hline \multicolumn{5}{|c|}{ AREA CHEIA } \\
\hline Taxons & Paratudal & Canjiqueiral & Espinheiral & Mata ciliar \\
\hline Hymenoptera & 81 & 84 & 69 & 19 \\
\hline Lepidoptera & 25 & 12 & 17 & 2 \\
\hline Diptera & 32 & 23 & 26 & 11 \\
\hline Coleoptera & 38 & 26 & 20 & 10 \\
\hline Hemiptera & 41 & 19 & 30 & 15 \\
\hline Orthoptera & 6 & 3 & 7 & 4 \\
\hline Aranae (Arachnida) & 5 & 7 & 9 & 6 \\
\hline$N^{*}$ & 228 & 174 & 178 & 67 \\
\hline $\mathrm{S}^{* *}$ & 7 & 7 & 7 & 7 \\
\hline Riqueza de Margalef & 2.545 & 2.678 & 2.666 & 3.286 \\
\hline \multicolumn{5}{|c|}{$\begin{array}{l}\text { * Numero total de indivíduos } \\
\text { ** Numero total de Táxons }\end{array}$} \\
\hline \multicolumn{5}{|c|}{$\begin{array}{l}\text { A riqueza das áreas é muito próxima, na área seca tem-se } \mathrm{R}= \\
3 \text { e, na área cheia, tem-se } \mathrm{R}=2.135 \text {. Isso se deve ao fato de este } \\
\text { e levar em consideração somente o número total de morfoes- } \\
\text { es entre as áreas comparadas. A verificação dessa diferença na } \\
\text { buição dessas morfoespécies em relação às áreas de coleta pode } \\
\text { elacionada com o ambiente em geral, áreas com vegetação mais } \\
\text { as que outras ou bordas apresentando vegetação mais esparsa, } \\
\text { e possibilita melhor área para voo desses insetos e a busca de } \\
\text { entos (Tabela 8). A quantidade de parasitoides e predadores } \\
\text { sempre relacionada à abundância de presas e hospedeiros, e a } \\
\text { bilidade de encontrá-los. }\end{array}$} \\
\hline
\end{tabular}


Tabela 8 - Índice de Diversidade de Riqueza de Margalef de Ordens (Morfoespécies) de insetos e aracnídeos capturados em armadilhas Malaise nos períodos: seca e cheia, em diferentes fisionomias no Pantanal, Corumbá, MS, no período de abril e maio de 2013

\section{Total de Morfoespécies}

\begin{tabular}{lcc} 
Táxons & SECA & CHEIA \\
\hline Hymenoptera & 427 & 253 \\
Lepidoptera & 66 & 56 \\
Diptera & 96 & 92 \\
Coleoptera & 101 & 94 \\
Hemiptera & 93 & 105 \\
Orthoptera & 14 & 20 \\
Aranae (Arachnida) & 12 & 27 \\
$\mathrm{~N}^{*}$ & 809 & 647 \\
$\mathrm{~S}^{* *}$ & 7 & 7 \\
\hline Riqueza de Margalef & 2.063 & 2.135 \\
\hline
\end{tabular}

* Numero total de indivíduos

**Numero total de Táxons

Para as aranhas, observou-se maior diversidade de espécies na época das águas, sendo maior no Paratudal, do que nas demais fisionomias. Como são predadores, generalistas, nessa fisionomia encontram-se maiores abundâncias de insetos, portanto maior quantidade de presa em potencial.

Pesquisas com separação de grupos mais específicos até Família, gênero ou Espécie, são necessários em estudos futuros, para, assim, entender melhor a dinâmica de cada grupo, dentro de seus hábitos alimentares e comportamental em geral. 


\section{CONCLUSÕES}

O Pantanal apresenta diferenças de diversidade e abundância, tanto em indivíduos como em morfoespécies de Ordens de insetos nas fisionomias dos locais nos períodos de seca e cheia.

As fisionomias estudadas apresentam diferenças tanto em relação ao número de indivíduos encontrados, quanto à sua diversidade. E maiores abundâncias foram encontrados no Paratudal, seguido do Espinheiral e sempre menores na Mata Ciliar.

Aranhas coletadas em armadilhas de Malaise foram capturadas em maior número no Paratudal e Cangiqueiral, com maiores números na época seca.

Diagnosticaram-se poucas diferenças nos índices de diversidade, abundância e riqueza entre a coletas na cheia e seca, indicando a adaptação das espécies nas duas épocas.

A Ordem Hymenoptera foi a mais abundante em todas as fisionomias dos ambientes no período de seca e cheia, quando considerada a Família Formicidae. A Ordem Diptera apresentou um percentual menor em relação à Ordem Hymenoptera, tanto no período de seca, quanto no período de cheia.

Os períodos de seca e cheia apresentam diversidade e abundância diferentes nas fisionomias. Maiores índices são encontrados no Paratudal e Cangiqueiral, com exceção de Hemiptera e Orthoptera.

\section{REFERÊNCIAS}

ADÁMOLI, J. O Pantanal e suas relações fitogeográficas com os cerrados: discussão sobre o conceito de complexo do Pantanal. In: CONGRESSO NACIONAL DA SOCIEDADE BOTÂNICA DO BRASIL, 32. Anais... Teresina: Universidade Federal do Piauí, 1982.

ALFONSI, R. R; CAMARGO, M. D. Condições climáticas para a região do Pantanal Mato-grossense. In: SIMPÓSIO SOBRE RECURSOS NATURAIS E 
Diversidade de insetos e aranhas presentes em diferentes fisionomias no Pantanal, na seca e cheia, Corumbá, MS

SÓCIO-ECONÔMICOS DO PANTANAL, 1. Anais... Brasília: EMBRAPA/CPAP, 1986. p. 29-42.

ALLABY, M. The Concise Oxford dictionary of botany. Oxford: Oxford University Press, 1992. 442p.

ALMEIDA, S. D. et al. Cerrado: espécies vegetais úteis. Planaltina, DF: Embrapa-CPAC, 1998. 464 p.

ALMEIDA, N. D. P. Segmentação do turismo no pantanal sul-matogrossense. 2002. 135 f. Dissertação (Mestrado em Desenvolvimento Local) - Universidade Católica Dom Bosco (UCDB), Campo Grande, MS, 2002.

AMADOR, G. D. A. Composição florística e caracterização estrutural de duas áreas de carandazais nas sub-regiões do Miranda e Nabileque, Pantanal Sul-Mato-Grossense, Brasil. 2006. Dissertação (Mestrado em Ecologia) - Universidade Federal de Mato Grosso do Sul, Campo Grande, MS, 2006.

AOKI, C. et al. Diversidade de abelhas (Hymenoptera: Apoidea) e recursos florais na RPPN Engenheiro Eliezer Batista, Pantanal de Mato Grosso do Sul. In: RABELO, A. et al. (Org.). Descobrindo o paraíso: aspectos biológicos da Reserva Particular do Patrimônio Natural Engenheiro Eliezer Batista. Rio de Janeiro: Instituto Homem Pantaneiro, 2012. p. 84-110.

BELLO, A. M. de; AOKI, C.; VIEIRA, L. Besouros (Coleoptera) da Reserva Particular do Patrimônio Natural Engenheiro Eliezer Batista. In: RABELO, A. et al. (Org.). Descobrindo o paraíso: aspectos biológicos da Reserva Particular do Patrimônio Natural Engenheiro Eliezer Batista. Rio de Janeiro: Instituto Homem Pantaneiro, 2012. p. 132-151.

BRASIL. Ministério do Interior. Estudos de desenvolvimento integrado da Bacia do Alto Paraguai (EDIBAP): Relatório da 1a fase. Descrição física e recursos naturais. Brasília, t. 2, 235p., 1972.

BRENER, A. G. F.; SILVA, J. F. Leaf-cutting ants and forest groves in a tropical parkland savanna of Venezuela: facilitated succession? Journal of Tropical Ecology, v. 11, n. 4, p. 651-669, 1995.

BROWN, K. S. Insetos como rápidos e sensíveis indicadores de uso sustentável de recursos naturais. In: MARTOS, H. L.; MAIA, N. B. (Ed.). Indicadores ambientais. Sorocaba, SP: PUC/Shell Brasil, 1997. p. 143-151. 
CARVALHO, C. D. et al. Diptera. In: RAFAEL, J. A. (Ed.). Insetos do Brasil: diversidade e taxonomia. Ribeirão Preto, SP: Holos, 2012. p. 701-743.

CASTELNOU, A. M. N. et al. Sustentabilidade socioambiental e diálogo de saberes: o Pantanal Mato-grossense e seu espaço vernáculo como referência. Desenvolvimento e Meio Ambiente, Curitiba, PR, n. 7, p. 41-67, jan.jun. 2003.

COUTINHO, L. M. Aspectos ecológicos da saúva no cerrado. A saúva, as queimadas e sua possível relação na ciclagem de nutrientes minerais. Boletim de Zoologia da Universidade de São Paulo, v. 8, n. 1, p. 1-9, 1984.

CROZIER, R. H. Evolutionary genetics of the Hymenoptera. Annual Review of Entomology, v. 22, n. 1, p. 263-288, 1997.

DALLING, J. W.; WIRTH, R. Dispersal of Miconia argentea seeds by the leaf-cutting ant Atta colombica. Journal of Tropical Ecology, v. 14, n. 5, p. 705-710, 1998.

DEMÉTRIO, M. F.; SILVESTRE, R.; AOKI, C. Formigas (Hymenoptera: Formicidae) da Reserva Particular do Patrimônio Natural Engenheiro Eliezer Batista, Descobrindo o Paraíso Aspectos Biológicos da Reserva Particular do Patrimônio Natural. Rio de Janeiro: Instituto Homem Pantaneiro, 2012. 182p.

DIDHAM, R. K. Dipteran tree-crown assemblages in a diverse southern temperate rain forest. In: STORK, N. E.; ADIS, J.; DIDHAM, R.K. (Ed.). Canopy arthropods. London: Chapman \& Hall, 1997. p. 320-343.

DUTRA, R. R.; MARINONI, R. C. Insetos capturados com armadilha Malaise na Ilha do Mel, Baía de Paranaguá, Paraná, Brasil. I Composição de Ordens. Revista Brasileira de Zoologia, v. 11, n. 2, p. 227-245, 1994.

GALLO, D. et al. Entomologia agrícola. Piracicaba, SP: FEALQ, 2002. 920p.

GARLET, J.; ROMAN, M.; COSTA, E. C. Levantamento da entomofauna de copa associada a diferentes espécies florestais. In: CONGRESSO REGIONAL DE INICIAÇÃO CIENTÍFICA E TECNOLÓGICA EM ENGENHARIA - CRICTE, 21. Anais... Ijuí, RS: UNIJUÍ, 2006.

GAULD, I. D.; BOLTON, B. (Ed.). The Hymenoptera. Oxford: Oxford University Press and The Natural History Museum, 1988. 332p.

LEAL, I. R. Dispersão de sementes por formigas na caatinga. In: LEAL, I. R.; TABARELLI, M.; SILVA, J. M. C. da (Ed.). Ecologia e conservação da caatinga. Recife, PE: Editora da UFPE, 2003. p. 593-624. 
Diversidade de insetos e aranhas presentes em diferentes fisionomias no Pantanal, na seca e cheia, Corumbá, MS

LEAL, I. R.; OLIVEIRA, P. S. Interactions between Fungus-Growing Ants (Attini), Fruits and Seeds in Cerrado Vegetation in Southeast Brazil1. Biotropica, v. 30, n. 2, p. 170-178, 1998.

LEVEY, D. J.; BYRNE, M. M. Complex ant-plant interactions: rain-forest ants as secondary dispersers and post-dispersal seed predators. Ecology, v. 74, n. 6, p. 1802-1812, set. 1993.

LORENZI, H. Árvores brasileiras: manual de identificação e cultivo de plantas arbóreas nativas do Brasil. Nova Odessa, SP: Plantarum, 1992. 352p.

MCGEOCH, M. A. The selection, testing and application of terrestrial insects as bioindicators. Biological Reviews of the Cambridge Philosophical Society, v. 73, n. 2, p. 181-201, 1998.

MOUTINHO, P. R. et al. Formigas e floresta: estudo para a recuperação de áreas de pastagem. Ciência Hoje, n. 15, p. 59-60, 1993.

OBER, H. K.; HAYES, J. P. Influence of forest riparian vegetation on abundance and biomass of nocturnal flying insects. Forest Ecology and Management, v. 256, n. 5, p. 1124-1132, 2008.

OLIVEIRA, A. K. M.; SCHELEDER, L. J. D.; FAVERO, S. Caracterização morfológica, viabilidade e vigor de sementes de Tabebuia chrysotricha (Mart. ex. DC.) Standl. Revista Árvore, Viçosa, MG, v. 32, n. 6, p. 1011-1018, nov./dez. 2008.

OLIVEIRA, C. M.; MORÓN, M. A.; FRIZZAS, M. R. Aegopsis bolboceridus (Coleoptera: Melolonthidae): an important pest on vegetables and corn in Central Brazil. Florida Entomologist, v. 91, n. 2, p. 324-327, 2008.

PIMENTA, A. Bioindicadores em Ecossistemas. 2008. Disponível em: <http:// www.herbario.com.br/dataherb06/1112bioindicad.htm>. Acesso em: fev. 2014.

POTT, A.; POTT, V. (Org.). Plantas do Pantanal. Corumbá, MS: EMBRAPA/ SPI, 1994. 320p.

PULZ, C. E. et al. Insetos- a importância do equilíbrio em um pomar cítrico - coleção didática do museu prof. Ramiro Gomes Costa. Revista Brasileira de Agroecologia, v. 2, n. 1, p. 741-744, fev. 2007

SANTOS, G. P. et al. Foraging of Parachartergus fraternus (Hymenoptera: Vespidae: Epiponini) on cloudy and sunny days. Sociobiology, v. 53, n. 2, p. 431, 2009. 
SANTOS, S. A. et al. Cheia e seca no Pantanal: importância do manejo adaptativo das fazendas. ADM - Artigo de Divulgação na Mídia, Embrapa Pantanal, Corumbá, MS, n. 120, p. 1-3, out. 2007. Disponível em: <http:// www.cpap.embrapa.br/publicacoes/online/ADM120.pdf>.

SILVA, R. C. Estudo do balanço de radiação no Pantanal sul matogrossense. 2003. Dissertação (Mestrado em Meteorologia) - Instituto Nacional de Pesquisas Espaciais (INPE), São José dos Campos, SP, 2003.

SILVA, M. S.; FONTENELLE, J. C.; MARTINS, R. P. Por que moscas visitam flores. Ciência Hoje, v. 30, n. 175, p. 68-71, 2000.

SILVEIRA NETO, S. et al. Manual de Ecologia dos insetos. São Paulo: Agronômica Ceres, 1976. 419p.

SOARES, J. J.; OLIVEIRA, A. K. M. D. The "paratudal" at the Pantanal de Miranda-Corumbá-MS, Brazil. Revista Árvore, Viçosa, MG, v. 33, n. 2, p. 339-347, mar./abr. 2009.

SOUZA, L. G. Bacia do Paraguai: geografia e história. Brasília: Departamento de Documentação e Divulgação, 1978.

SOUZA-SILVA, M. et al. Ecology, behavior and bionomics. Seasonal abundance and species composition of flower-visiting flies. Neotropical Entomology, Londrina, PR, v. 30, n. 3, p. 351-359, set. 2001.

THOMAZINI, M. J.; THOMAZINI, A. D. B. Levantamento de insetos e análise entomofaunística em floresta, capoeira e pastagem no sudeste acreano. Boletim de Pesquisa e Desenvolvimento, Rio Branco, AC, n. 35, set. 2002.

WIRTH, R. et al. Herbivory of leaf-cutting ants: a case study on Atta colombica in the Tropical Rainforest of Panama. Ecological Studies, n. 164, 230p., 2003. 